\title{
The Effects of Public Disclosure of Industry Payments to Physicians on Patient Trust: A Randomized Experiment
}

\author{
Alison R. Hwong, MD, $P h D^{1,2}$, Sunita Sah, MD, PhD, MBA ${ }^{3}$, and Lisa Soleymani Lehmann, MD, PhD ${ }^{4,5,6}$ \\ 'Department of Psychiatry, University of California, San Francisco, San Francisco, CA, USA; ${ }^{2}$ Harvard PhD Program in Health Policy and Harvard \\ Medical School, Boston, MA, USA; ${ }^{3}$ Johnson Graduate School of Management, Cornell University, Ithaca, NY, USA; ${ }^{4}$ Department of Medicine, \\ Brigham and Women's Hospital and Harvard Medical School, Boston, MA, USA; ${ }^{5}$ Department of Health Policy and Management, Harvard T. H. \\ Chan School of Public Health, Boston, MA, USA; ${ }^{6}$ National Center for Ethics in Health Care, Veterans Health Administration, Washington, DC, USA.
}

BACKGROUND: Financial ties between physicians and the pharmaceutical and medical device industry are common, but little is known about how patient trust is affected by these ties.

OBJECTIVE: The purpose of this study was to evaluate how viewing online public disclosure of industry payments affects patients' trust ratings for physicians, the medical profession, and the pharmaceutical and medical device industry.

DESIGN: This was a randomized experimental evaluation.

PARTICIPANTS: There were 278 English-speaking participants over age 18 who had seen a healthcare provider in the previous 12 months who took part in the study. INTERVENTIONS: Participants searched for physicians on an online disclosure database, viewed payments from industry to the physicians, and assigned trust ratings. Participants were randomized to view physicians who received no payment (\$0), low payment (\$250-300), or high payment $(>\$ 13,000)$ from industry, or to a control arm in which they did not view the disclosure website. They also were asked to search for and then rate trust in their own physician.

MAIN MEASURES: Primary outcomes were trust in individual physician, medical profession, and industry. These scales measure trust as a composite of honesty, fidelity, competence, and global trust.

KEY RESULTS: Compared to physicians who received no payments, physicians who received payments over $\$ 13,000$ received lower ratings for honesty [mean (SD): $3.36(0.86)$ vs. $2.75(0.95), p<0.001]$ and fidelity [3.19 (0.65) vs. 2.89 (0.68), $p=0.01$ ]. Among the $7.9 \%$ of participants who found their own physician on the website, ratings for honesty and fidelity decreased as the industry payment to the physician increased (honesty: Spearman's $\rho=-0.52, p=0.02$; fidelity: Spearman's $\rho=-0.55$, $p=0.01)$. Viewing the disclosure website did not affect trust ratings for the medical profession or industry.

CONCLUSIONS: Disclosure of industry payments to physicians affected perceptions of individual physician honesty and fidelity, but not perceptions of competence. Disclosure did not affect trust ratings for the medical profession or the pharmaceutical and medical device industry. ClinicalTrials.gov identifier: NCT02179632 (https:// clinicaltrials.gov/ct2/show/NCT02179632).

Electronic supplementary material The online version of this article (doi:10.1007/s11606-017-4122-y) contains supplementary material, which is available to authorized users.

Received November 15, 2016

Revised April 28, 2017

Accepted June 16, 2017

Published online July 17, 2017
$\mathrm{J}$ Gen Intern Med 32(11):1186-92

DOI: $10.1007 / \mathrm{s} 11606-017-4122-\mathrm{y}$

(c) Society of General Internal Medicine 2017

\section{INTRODUCTION}

Financial ties between physicians and pharmaceutical and medical device manufacturers are common. In 2012, onequarter of US doctors received payments from manufacturers, and nearly two-thirds of doctors accepted gifts of food. ${ }^{1}$ But policymakers and healthcare leaders have raised concerns that financial ties to industry have the potential to create conflicts of interest that could change physicians' behavior and affect patient $_{\text {care. }}{ }^{2-4}$ For example, pharmaceutical company payments to doctors have been associated with differences in prescribing behavior and the medications that physicians request for hospital formularies. ${ }^{5-7}$

Disclosure has been proposed as a mechanism for addressing concerns regarding financial conflicts of interest. ${ }^{8}$ Accordingly, in 2009, the Institute of Medicine published a report recommending disclosure as a form of public transparency in order to identify, limit, and manage potential conflicts. ${ }^{2}$ In 2010, the journalism group ProPublica launched a website that assembled reports on manufacturer payments to physicians and hospitals into a single public database. ${ }^{9}$ In 2014, a federal website, Open Payments, followed suit as a provision under the Affordable Care Act. This provision, known as the Physician Payments Sunshine Act, requires manufacturers of drugs, devices, biologics, and medical supplies covered by Medicare or Medicaid to report certain types of payments to the Centers for Medicare and Medicaid Services (CMS). ${ }^{10}$ This includes payments or gifts (plus research funding and investments) over $\$ 10$ given to physicians and teaching hospitals. Although the Open Payments website has faced criticism about its usability, the intention is to promote transparency and help patients become better informed consumers. ${ }^{1,11}$

However, little is understood about how such disclosures affect patient trust and decision-making. Patient-doctor trust is important; patients who report trust in their physician are more likely to take medications regularly, request and receive needed services, and have higher levels of satisfaction with their care. $^{12-19}$ Thus far, studies examining patient responses to 
disclosure of physician industry payments reveal contradictory findings, with some reporting that trust in physicians is increased, while others have shown reduced trust levels. ${ }^{20-24}$

The magnitude (hundreds vs. thousands of dollars) and category of payment (for example, research or speaking) may also affect patient trust. Patients tend to find gifts of large personal value, such as paid dinners and golf tournaments, less acceptable than those that could have a direct positive impact on patient care, like textbooks or free drug samples. ${ }^{25-27}$

The American Medical Association (AMA), healthcare systems, and at least five states plus the District of Columbia have created guidelines as to what they deem acceptable payment amounts for physicians. The AMA Code of Medical Ethics states that gifts "in the general range of $\$ 100$ are permissible," but the empirical basis for this guideline is lacking. ${ }^{28}$ In contrast, the Kaiser Permanente healthcare system defines "significant financial interest" for clinical researchers as remuneration exceeding $\$ 5000$ in a 12-month period. ${ }^{29}$ States such as Minnesota and Vermont have banned industry-sponsored meals or gifts, but not payments for research or speaking engagements. ${ }^{30,31}$

Our primary objective in this study was to evaluate differences in levels of trust in individual physicians, the medical profession, and industry after viewing, or not viewing, online public disclosures of varying industry payments to physicians across four study arms. Unlike previous studies that relied on hypothetical scenarios ${ }^{27}$ we used a live public disclosure website, allowing participants to view payments to physicians in the context of thousands of other physicians and teaching hospitals. Trust was measured using four dimensions: 1) fidelity, pursuing a patient's best interests; 2) competence, avoiding mistakes and producing the best results; 3 ) honesty, telling the truth; and 4) global trust, a holistic aspect. ${ }^{32-35}$ We hypothesized that transparency of financial ties to industry would lower patient perceptions of physician fidelity. ${ }^{36}$ In contrast, we hypothesized that physicians who receive payments for consulting may be viewed as experts in their fields, and thus may be seen as more competent. ${ }^{37}$ Therefore, we were interested not only in the aggregate trust score but also in the specific dimensions that comprise trust.

\section{METHODS}

\section{Participants}

The study took place in a behavioral research facility which maintains a participant pool of community members and university affiliates. Eligible participants were English-speaking adults over the age of 18 who had seen a doctor at least once in the 12 months preceding their participation in the study (since trust can differ between patients who are connected to the healthcare system and those who are not). ${ }^{19}$ To avoid priming, participants were told they were in a study about the internet and health. The study took place between January and March 2014 and received exemption from the Harvard
Medical School Institutional Review Board (IRB). The full trial protocol can be accessed at ClinicalTrials.gov.

Based on variance estimates from two previous studies using the same patient trust measures, to achieve $80 \%$ statistical power in detecting a 0.5 -point difference on the five-point Likert trust scales with a two-tailed alpha level of 0.05 , we needed a minimum of 148 participants across all four study arms (three Disclosure arms: No Payment, Low Payment, High Payment; one No Disclosure control arm). ${ }^{38,39}$

\section{Design and Interventions}

This study was a randomized experimental evaluation to evaluate patient trust in physicians, the medical profession, and industry in the context of a live disclosure website. The nonprofit group ProPublica's searchable payment website (http:// www.propublica.org) was chosen for its usability and completeness, compared to Open Payments, which was not fully functional at the time of study. ${ }^{40}$

There were four study arms. Participants were randomized using constrained randomization (in permuted blocks of 12, drawing numbers from a hat) to view physicians who received, in aggregate, 1) No Payment ( $\$ 0$, which means the physician's name was searched for, but did not appear, on the disclosure website), 2) Low Payment (\$250-300), or 3) High Payment (over \$13,000) from industry; or 4) to a No Disclosure (control) arm in which participants did not view the disclosure website (see online Appendix A1 for study design). ${ }^{41}$ In an effort to standardize other physician attributes as much as possible, physicians who were selected to be searched for were all senior male physicians practicing internal medicine in Massachusetts (due to evidence that patient trust can vary by physician gender). ${ }^{42,43}$ Payment amounts were chosen based on previous research on average industry payments to physicians and on focus groups that we conducted with pilot participants. ${ }^{44}$ Participants in the Low and High Payment arms were further divided into subgroups that viewed a physician who was paid for either research or speaking services. Information posted on the website included physician name, city and state, payment amount, payment date, company, and payment category (research or speaking).

Participants were given the name of the physician, asked to search for this individual, and then reported the amounts and types of industry payments received by this physician within the past year. The correct payment amounts and types were then displayed for the participant to ensure that they located and interpreted the information accurately. Participants subsequently completed a survey to measure the four dimensions of trust in the doctor they viewed, trust in the medical profession, and trust in the pharmaceutical industry. Finally, participants in the Disclosure arms looked up their own doctor on the website, reported any payments, and rated their trust in their own physician.

Participants in the control arm were not exposed to the disclosure website. Instead, they performed an online information-seeking task by looking up weather reports and recording findings on temperature. Therefore, they did not rate trust in individual physicians, but completed the trust 
questions for the medical profession and pharmaceutical industry. All participants answered demographic questions. Thirty-six exit interviews were conducted with randomly selected participants to evaluate comprehension of the tasks.

\section{Pilot Study}

The intervention and survey questions were refined through cognitive interviews, focus groups, and a pilot study. Pilot participants $(n=32)$ searched for physicians on the disclosure website and reported any difficulties with completing tasks. Interviews $(n=11)$ and focus groups $(n=32)$ assessed readability and comprehension of instructions and questions. They were asked: 1) Were the instructions clear? 2) Were the questions clear? and 3) Were there any problems in understanding what kind of answers were expected or in providing answers to the questions posed? They were also asked whether there was a threshold payment amount that would be considered "unacceptable" for their physician to receive from industry. Based on the pilot, we revised the task instructions for the full study so that participants could reliably complete the tasks.

\section{Main Measures}

The study used the ten-item Interpersonal Physician Trust Scale, the ten-item Patient Trust in the Medical Profession Scale, and an adapted nine-item scale for trust in pharmaceutical and medical device manufacturers (Trust in Industry; see online Appendix A2 for scales). ${ }^{32-34}$ The Physician and Medical Profession instruments have been formally validated and demonstrate excellent reliability (Cronbach's alpha = 0.94). ${ }^{33,35}$ The Trust in Industry scale was adapted from the Trust in Health Insurers scale. ${ }^{34}$ Wording was modified to reference the pharmaceutical and medical device industry, and the adapted scale was evaluated for internal validation after the pilot (Cronbach's alpha > 0.84). We also used a validated, abbreviated five-item Trust in Physicians scale, which consists of the four dimensions of trust (honesty, fidelity, competence, and global trust), for participants who found their own physician on the website. ${ }^{45}$ Participants responded on a five-point Likert scale, with 5 indicating greatest agreement. We report the four dimensions of trust as well as total trust, an aggregate score.

\section{Statistical Analyses}

The primary outcomes were trust ratings (honesty, fidelity, competence, global trust) for individual doctors, the medical profession, and industry. We analyzed participant characteristics using $\chi^{2}$ tests for categorical variables and analysis of variance for continuous variables.

To evaluate physician trust, we conducted analyses of variance (ANOVAs) with trust ratings as the dependent variable and payment amount as the independent variable, followed by planned pairwise comparisons (using Tukey's test) of trust ratings between payment amount arms. Since each trust dimension was a separate construct, Tukey's multiple comparison adjustment was made within each dimension but not across dimensions. For trust in the medical profession and industry, we conducted ANOVAs with trust ratings as the dependent variable and Disclosure condition (being exposed vs. not being exposed to the disclosure website) as the independent variable. For trust in one's own physician, the Wilcoxon rank-sum test was used (for non-normal distribution) to evaluate correlations between payment amount and trust. We controlled for race in all analyses. Statistical analyses were performed using Stata (Stata Statistical Software, Release 14; StataCorp LP, College Station, TX).

\section{RESULTS}

Table 1 shows the characteristics and number of participants by arm. The research facility invited a randomly selected portion (40\%) of 1953 eligible study participants (Fig. 1). The first 369 people to enroll were scheduled into a study session; 91 failed to show up for the scheduled session, resulting in a $75 \%$ completion rate (278 participants). Participant characteristics did not differ significantly by study arm, except for race $\left(\chi^{2}=13.49, p=0.04\right)$. Controlling for race did not change the statistical significance of the outcome measures. There were no significant differences in trust ratings by payment type (research vs. speaking, all $p s>0.14$ ), so participants in these categories were grouped together in the analyses.

\section{Task Completion and Website Difficulty}

All participants who began the study completed the tasks. Ten percent (24/240) of participants in the Disclosure arms did not find the correct answers when searching for payments. Exit interviews revealed that these individuals had difficulty using the website search function. All participants were shown the correct payment information before responding to trust measures.

\section{Trust in Individual Physicians, Medical Profession, and Industry}

There was a significant effect of the amount of physician payments across the three Disclosure arms (No Payment, Low Payment, and High Payment) on average honesty, fidelity, and total trust ratings, where total trust is the composite score of the four dimensions (Table 2 and Fig. 2). Planned pairwise comparisons (using Tukey's test adjusting for multiple comparisons) revealed that physicians who did not receive any payments were rated, on average, significantly higher in honesty, fidelity, and total trust than physicians who received high payments of $\$ 13,000-15,000$ (Table 3). There were no significant differences in trust for comparisons between physicians who received No Payment versus Low Payment (\$250-300), or between physicians who received High Payment $(\$ 13,000-15,000)$ versus Low Payment. There were also no significant differences in ratings for competence or global trust between any payment amounts. 
Table 1 Participant Characteristics by Study Arm

\begin{tabular}{|c|c|c|c|c|c|}
\hline Variable & $\begin{array}{l}\text { No Disclosure } \\
(n=38)\end{array}$ & $\begin{array}{l}\text { No Payment } \\
(n=80)\end{array}$ & $\begin{array}{l}\text { Low Payment } \\
(n=80)\end{array}$ & $\begin{array}{l}\text { High Payment } \\
(n=80)\end{array}$ & $\overline{p \text { value }}$ \\
\hline Women, no. $(\%)$ & $23(61)$ & $41(52)$ & $45(56)$ & $40(50)$ & 0.69 \\
\hline Age, mean $( \pm \mathrm{SD})$, years & $34.6(15.2)$ & $33.5(15.5)$ & $34.4(15.1)$ & $34.7(17.3)$ & 0.97 \\
\hline White only, non-Hispanic, no. (\%) & $17(45)$ & $46(58)$ & $53(67)$ & $56(70)$ & 0.04 \\
\hline Less than college education, no. (\%) & $17(45)$ & $41(51)$ & $37(46)$ & $41(51)$ & 0.84 \\
\hline Full-time employment, no. (\%) & $12(32)$ & $13(16)$ & $17(21)$ & $16(20)$ & 0.31 \\
\hline Income under $\$ 15,000$, no. $(\%)$ & $12(32)$ & $29(36)$ & $29(36)$ & $32(40)$ & 0.85 \\
\hline Self-reported health, mean $( \pm \mathrm{SD})^{*}$ & $3.97(0.79)$ & $3.94(0.88)$ & $3.85(1.02)$ & $3.96(0.91)$ & 0.85 \\
\hline Self-reported mental health, mean $( \pm S D)$ & $3.87(0.99)$ & $3.71(1.06)$ & $3.71(1.01)$ & $3.74(1.06)$ & 0.87 \\
\hline
\end{tabular}

Note: Not all participants answered all demographics questions, so the denominator may vary in some categories. *For self-reported health and mental health: $1=$ poor, $5=$ excellent

For trust in the medical profession and industry, planned comparisons between the three Disclosure arms (No Payment, Low Payment, and High Payment) revealed no significant differences based on payment amount $(p>0.20)$. We also compared all three Disclosure arms together to the No Disclosure arm to examine whether simple exposure to the disclosure website would influence participants' trust in the medical profession and industry compared to no exposure to the website. There were no significant differences between Disclosure and No Disclosure arms for any trust dimensions for the medical profession or industry. Average total trust ratings $( \pm \mathrm{SD})$ for the medical profession were $2.96(0.68)$ by

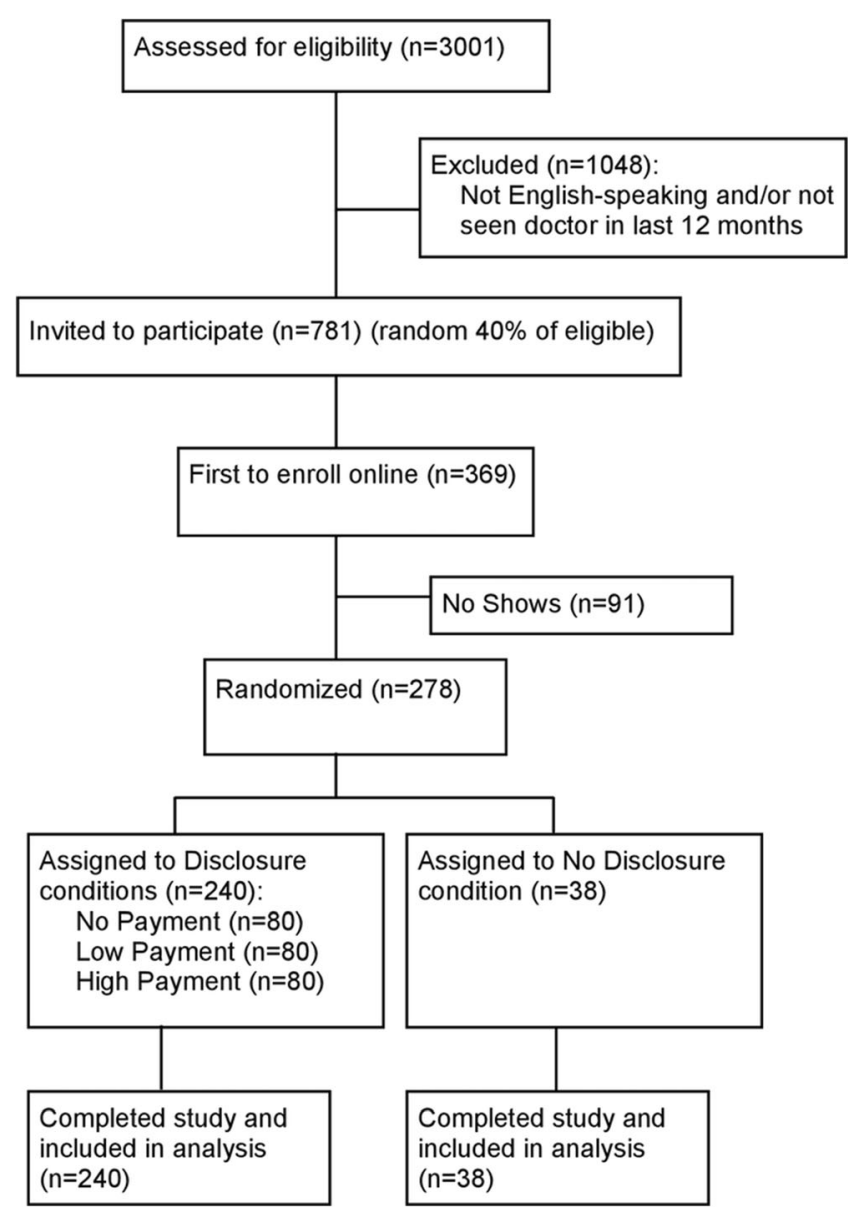

Figure 1 CONSORT study flow diagram participants exposed to the disclosure website versus 3.09 (0.56) by participants not exposed to disclosure (No Disclosure; $d f=2, F=1.13, p=0.29$ ). For the pharmaceutical and medical device industry, average total trust ratings were 2.48 (0.63) for exposure to disclosure versus 2.68 (0.68) for No Disclosure $(d f=2, F=2.89 p=0.09)$.

\section{Trust in One's Own Doctor}

Nineteen participants in the Disclosure arms $(19 / 240=7.9 \%)$ found their own doctors listed on the disclosure website. This subgroup of participants did not differ significantly in distribution from the rest of the participants based on study arm assignment $(Z=-1.86, p=0.06)$, race $(Z=-0.27, p=0.79)$, gender $(Z=-0.19, p=0.85)$, education $(Z=-0.29, p=0.77)$, or income $(Z=-0.08, p=0.94)$. Payments for these doctors ranged from $\$ 11$ to $\$ 59,880$ (median payment $\$ 250$, interquartile range $\$ 1900$ ). There was a negative correlation between payment amount received by the physician and the honesty rating given to that physician (Spearman's $\rho,-0.52$; $p=0.02$ ), payment amount and fidelity (Spearman's $\rho,-0.55$; $p=0.01$ ), and payment amount and total trust (Spearman's $\rho$,

Table 2 Mean (SD) and Analysis of Variance for Trust in Individual Physicians

\begin{tabular}{lllll}
\hline \hline $\begin{array}{l}\text { Dimensions } \\
\text { of trust }\end{array}$ & $\begin{array}{l}\text { No } \\
\text { Payment }\end{array}$ & $\begin{array}{l}\text { Low } \\
\text { Payment }\end{array}$ & $\begin{array}{l}\text { High } \\
\text { Payment }\end{array}$ & Statistic \\
\hline Honesty & $3.36(0.86)$ & $3.06(0.93)$ & $2.75(0.95)$ & $\begin{array}{l}d f=2, \\
F=8.49, \\
p=0.0003\end{array}$ \\
Fidelity & $3.19(0.65)$ & $3.06(0.63)$ & $2.89(0.68)$ & $\begin{array}{l}d f=2, \\
F=4.33, \\
p=0.01\end{array}$ \\
Competence & $3.17(0.59)$ & $3.24(0.68)$ & $3.06(0.64)$ & $\begin{array}{l}d f=2, \\
F=1.54 \\
p=0.22\end{array}$ \\
Global trust & $2.97(0.69)$ & $2.83(0.79)$ & $2.73(0.86)$ & $\begin{array}{l}d f=2, \\
F=1.83, \\
p=0.16\end{array}$ \\
Total trust & $3.13(0.58)$ & $3.05(0.60)$ & $2.88(0.65)$ & $\begin{array}{l}d f=2, \\
F=3.54, \\
p=0.03\end{array}$ \\
\hline
\end{tabular}

Scores are averages for ratings on five-point Likert scale, with 1 as lowest and 5 as highest trust rating. Total trust score is the aggregate of the four dimensions. Statistic is for analysis of variance controlling for race of participants. Participants who did not view the disclosure website (No Disclosure) are not included here, as they did not search for or rate trust in an individual physician. 


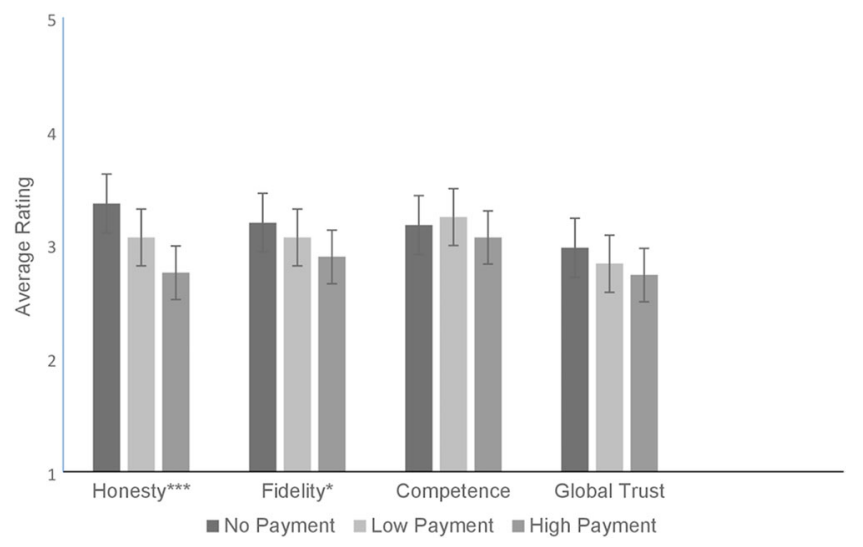

Figure 2 Average trust ratings for individual physicians. Ratings are based on five-point Likert scale ( 1 = lowest trust, 5 = highest trust).

Whiskers represent standard error. Significance indicates that analysis of variance results found differences in trust ratings across payment conditions. $* p<0.05, * * * p<0.001$. All analyses controlled for race.

$-0.51 ; p=0.03)$. There were no significant correlations between the payment amount and competence or global trust $(p>0.16)$. Based on the median payment for this group $(n=19)$, we split the payments into "low" payment $(\leq \$ 250)$ and "high" payment (> \$250). The average total trust rating for the "high" payment physician group (3.27, SD: 0.95) was significantly lower than that for the "low" payment physician group (4.16, SD: 0.67; Wilcoxon rank-sum: $z, 2.26$; prob $>|z|$ $=0.02$ ). Fidelity ratings were also lower for doctors receiving payments over $\$ 250$ versus $\$ 250$ or less (Wilcoxon rank-sum:

Table 3 Comparisons of Trust Ratings for Individual Physicians Based on Payment Amount

\begin{tabular}{|c|c|c|c|c|}
\hline $\begin{array}{l}\text { Dimension } \\
\text { of Trust }\end{array}$ & Comparison & $\begin{array}{l}\text { Mean } \\
\text { difference }\end{array}$ & $\begin{array}{l}\text { Standard } \\
\text { error }\end{array}$ & $\begin{array}{l}p \\
\text { value }\end{array}$ \\
\hline \multirow[t]{3}{*}{ Honesty } & No Payment > & 0.60 & 0.15 & \\
\hline & High Payment & 0.29 & 0.15 & $\begin{array}{l}0.001 \\
0.11\end{array}$ \\
\hline & $\begin{array}{l}\text { Low Payment } \\
\text { > High } \\
\text { Payment }\end{array}$ & 0.31 & 0.14 & 0.09 \\
\hline \multirow[t]{3}{*}{ Fidelity } & $\begin{array}{l}\text { No Payment > } \\
\text { High Payment }\end{array}$ & 0.92 & 0.31 & 0.01 \\
\hline & $\begin{array}{l}\text { No Payment }> \\
\text { Low Payment }\end{array}$ & 0.40 & 0.31 & 0.41 \\
\hline & $\begin{array}{l}\text { Low Payment } \\
>\text { High } \\
\text { Payment }\end{array}$ & 0.52 & 0.31 & 0.21 \\
\hline \multirow[t]{3}{*}{ Total trust } & $\begin{array}{l}\text { No Payment > } \\
\text { High Payment }\end{array}$ & 0.25 & 0.10 & 0.03 \\
\hline & $\begin{array}{l}\text { No Payment }> \\
\text { Low Payment }\end{array}$ & 0.09 & 0.10 & 0.63 \\
\hline & $\begin{array}{l}\text { Low Payment } \\
>\text { High } \\
\text { Payment }\end{array}$ & 0.17 & 0.10 & 0.20 \\
\hline
\end{tabular}

Pairwise comparisons using Tukey's test were performed for trust dimensions with statistically significant $(p<0.05)$ ANOVA results. All comparisons controlled for race. $z, 2.10$; prob $>|z|=0.04)$. The $t$-tests for lower honesty ratings did not quite reach statistical significance (Wilcoxon ranksum: $z,-1.92 ;$ prob $>|z|=0.055$ ).

\section{DISCUSSION}

This study provides a demonstration of the potential consequences of a national live physician payment disclosure website with regard to patient trust in individual doctors, the medical profession, and industry. Similar to previous studies that used hypothetical scenarios (rather than actual disclosure websites) we found that the higher the payment a physician received from industry, the lower the ratings for certain aspects of trust. In our study, physicians who received high payments were perceived to be less honest and less committed to the best interests of patients than physicians who received no payments. In contrast to other experimental work, competence ratings were not affected by viewing payment disclosure. ${ }^{27}$ Interestingly, out of 240 participants, only $7.9 \%$ of those who searched for their own physicians found them. However, viewing their own physicians on the disclosure website was associated with a decrease in fidelity and honesty ratings as the amount of payments received by their physicians increased. Yet there was no significant effect of payment disclosure on trust in the medical profession or in the pharmaceutical and medical device industry, suggesting that participants may hold individual physicians most accountable for accepting industry payments.

While payment magnitude appeared to affect trust ratings for physicians, the category of payment (research vs. speaking) did not. However, more specific and varied categories may reveal differences, as previous research has found that physicians who received in-kind payments in the form of free drug samples were viewed as favorably as physicians who received no payments. ${ }^{27}$

One limitation of our study was that only a small number of participants found their own physicians on the website (about $8 \%$ ). The Open Payments website incorporates payment information from a greater number of companies than the ProPublica website, so more patients may find their physicians on that website. But difficulty in website use was also an issue, with $10 \%$ of our participants unable to complete the search task, and the ProPublica website has been reported as being more user-friendly than the Open Payments website. ${ }^{1}$ This finding suggests that patients may struggle to obtain accurate information about their providers. In addition, our study does not address the question of whether the public will use the website as intended to obtain information about healthcare providers.

Our respondents were well-educated and living in the northeastern United States, which may limit the generalizability of our findings. However, these participants could also represent the subpopulation of patients who would be interested in accessing disclosure databases to act as informed consumers. 
Other data on providers, such as quality ratings and training, may also inform a patient's level of trust. We also note that despite randomization, there was a difference in distribution of participant race across study arms, though controlling for race did not change our results. Finally, whether the differences in trust ratings found in our study will lead to clinically meaningful outcomes remains to be seen.

While arguments in favor of payment disclosure have focused on the value of transparency and informing consumers of health services, it is unclear how many patients will actively use the website. ${ }^{10,46-48}$ Disclosure may, however, cause physicians to change their behavior. Physicians may be reluctant to accept industry payments if they learn that patient awareness of and access to payment information can have a negative impact on their patients' trust. ${ }^{49,50}$ This deterrent effect could be the primary means of reducing potential financial conflicts of interest through disclosure.

Collaborations between industry and medicine have the potential to advance patient care and public health. The challenge is in determining how the medical profession can promote innovation without creating undue influence or bias, and while maintaining public trust in physicians. Further research is needed to assess the complex relationship among industry payments to physicians, patient-doctor trust, and clinical outcomes.

\section{Acknowledgements:}

Contributors: The authors wish to thank Stuart Lipsitz, ScD, head of Biostatistical Services at the Center for Surgery and Public Health at Brigham and Women's Hospital (Boston, MA), for his help with statistical programming and analysis, and Martha Shumway, $\mathrm{PhD}$, Associate Professor, Department of Psychiatry, UCSF School of Medicine (San Francisco, CA), for statistical consultation. Neither contributor received compensation for their contributions.

Corresponding Author: Alison R. Hwong, MD, PhD; Department of PsychiatryUniversity of California, San Francisco, San Francisco, CA, USA (e-mail: alison.hwong@ucsf.edu).

Compliance with Ethical Standards:

Funders: Financial support for this study was provided by the Edmond J. Safra Center for Ethics, Harvard University, and Brigham and Women's Hospital Department of Medicine. The funding agreement ensured the authors' independence in designing the study, interpreting the data, and writing and publishing the report.

Conflict of Interest: The authors declare that they do not have a conflict of interest. The content of this article is solely the responsibility of the authors and does not represent the official views of the Veterans Health Administration, the National Center for Ethics in Health Care, the U.S. government, Harvard Catalyst, Harvard University and its affiliated academic healthcare centers, or the National Institutes of Health.

\section{REFERENCES}

1. Ornstein, C. Another Government Website Rollout That Is Found Wanting. The New York Times. October 1, 2014. Available from: http:// nyti.ms/YOOLOE. Accessed May 20, 2017.

2. Institute of Medicine. Conflict of interest in medical research, education and practice. Washington, DC: National Acad. Press; 2009.
3. Lo B, Ott C. What is the enemy in CME, conflicts of interest or bias? JAMA. 2013;310:1019-1020.

4. Sah S. Conflicts of interest and your physician: Psychological processes that cause unexpected changes in behavior. J Law Med Ethics. 2012;40:482-487.

5. Wazana A. Physicians and the pharmaceutical industry: is a gift ever just a gift? JAMA. 2000;283:373-80.

6. Chren MM, Landefeld CS. Physicians' behavior and their interactions with drug companies. A controlled study of physicians who requested additions to a hospital drug formulary. JAMA. 1994;271:684-9.

7. Orlowski JP, Wateska $\mathbf{L}$. The effects of pharmaceutical firm enticements on physician prescribing patterns. There's no such thing as a free lunch. Chest. 1992;102:270-3.

8. Richardson E. Health Policy Brief: The Physician Payments Sunshine Act. October 2, 2014. In: Health Affairs. Available from: http://www. healthaffairs.org/healthpolicybriefs/brief.php?brief_id=127. Accessed May 20, 2017.

9. Ornstein C, Weber T, Nguyen D. About Dollars for Docs data. March 11, 2013. In: ProPublica. Available from: http://www.propublica.org/article/ about-our-pharma-data. Accessed May 20, 2017

10. Centers for Medicare and Medicaid Services. Medicare, Medicaid, Children's Health Insurance Programs: transparency reports and reporting of physician ownership or investment interests. Fed Regist. 2013;78:94579528.

11. Caldwell T, Robertson C. Open Payments: early impact and the next wave of reform. Health Affairs Blog. March 3, 2015. Available from: http://healthaffairs.org/blog/2015/03/03/open-payments-early-impact-and-the-next-wave-of-reform/. Accessed May 20, 2017.

12. Blackstock OJ, Addison DN, Brenna JS, Alao OA. Trust in primary care providers and antiretroviral adherence in an urban HIV clinic. J Health Care Poor Underserved. 2012;23:88-98.

13. Bonds DE, Camacho F, Bell RA, Duren-Winfield VT, Anderson RT, Goff DC. The association of patient trust and self-care among patients with diabetes mellitus. BMC Fam Pract. 2004;5:26.

14. Safran DG, Montgomery JE, Chang H, Murphy J, Rogers WH. Switching doctors: Predictors of voluntary disenrollment from a primary physician's practice. J Fam Pract. 2001;50:130-6.

15. Bratton C, Chavin K, Baliga P. Racial disparities in organ donation and why. Curr Opin Organ Transplant. 2011;16:243-9.

16. Musa D, Schulz R, Harris R, Silverman M, Thomas SB. Trust in the health care system and the use of preventive health services by older black and white adults. Am J Public Health. 2009;99:1293-1299.

17. Thom DH, Kravitz RL, Bell RA, Krupat E, Azari R. Patient trust in the physician: relationship to patient requests. Family Practice. 2002;19:476-483

18. Baker R, Mainous AG, Gray DP, Love MM. Exploration of the relationship between continuity, trust in regular doctors and patient satisfaction with consultations with family doctors. Scand J Primary Health Care. 2003;21:27-32.

19. Thom DH, Hall MA, Pawlson LG. Measuring patients' trust in physicians when assessing quality of care. Health Aff (Millwood). 2004;23:124-132.

20. Loewenstein G, Sah S, Cain DM. The unintended consequences of conflict of interest disclosure. JAMA. 2012;307:669-670.

21. Sah S, Cain D, Loewenstein G. Confessing one's sins but stil committing them: Transparency and the failure of disclosure. In Oliver AJ, ed. Essays in Behavioural Public Policy. Cambridge: Cambridge University Press; 2013.

22. Tattersall MHN, Dimoska A, Gan K. Patients expect transparency in doctors' relationship with the pharmaceutical industry. Med J Aust. 2009; 190:65-58.

23. Sah S, Loewenstein G, Cain D. Insinuation anxiety: Concern that advice rejection will signal distrust after conflict of interest disclosures. Working Paper. 2015. http://media.wix.com/ugd/4aa 4 b 7 _ ac680ce8d4224a46ab1f8cc54b684ab8.pdf. Accessed May 20, 2017.

24. Wolston, M. An MS Patient Loses Trust When She Finds Out Her Doctor Is Paid By Drug Companies. Health Aff (Millwood). 2011;30:2449-52.

25. Jastifer J, Roberts S. Patients' awareness of and attitudes toward gifts from pharmaceutical companies to physicians. Int $\mathrm{J}$ Health Serv. 2009;39:405-414.

26. Licurse A, Barber E, Joffe S, Gross C. The impact of disclosing financia ties in research and clinical care: a systematic review. Arch Intern Med. 2010;170:675-82.

27. Perry JE, Cox D, Cox A. Trust and Transparency: Patient Perceptions of Physicians' Financial Relationships with Pharmaceutical Companies. J Law Med Ethics. 2014;42:475-491.

28. Grande D. Limiting the influence of pharmaceutical industry gifts on physicians: self-regulation or government intervention? JGIM. 2010;25:79-83. 
29. Kaiser Permanente. Policy on conflicts of interest in research. Effective August 25, 2011. Available from: goo.gl/26bHdJ. Accessed May 20, 2017.

30. State of Vermont, Office of the Attorney General. Prescribed Products Gift Ban and Disclosure Law, Act 51, No. 51, S. 104. Effective May 26, 2011. Available from: http://www.leg.state.vt.us/docs/2012/Acts/ACT051. pdf. Accessed May 20, 2017.

31. Gifts to Practitioners Prohibited, Minnesota Statutes, Section 151.461. 2015. Available from: https://www.revisor.mn.gov/statutes/?id=151. 461. Accessed May 20, 2017.

32. Hall MA, Dugan E, Zheng B, Mishra AK. Trust in physicians and medical institutions: what is it, can it be measured, and does it matter? Milbank Q. 2001;79:613-39.

33. Hall MA, Camacho F, Dugan E, Balkrishnan R. Trust in the medical profession: conceptual and measurement issues. HSR. 2002;37:1419-39.

34. Zheng B, Hall MA, Dugan E, Kidd KE, Levine D. Development of a scale to measure patients' trust in health insurers. HSR. 2002;27:185-200.

35. Hall MA, Zheng B, Dugan E, Camacho F, Kidd KE, Mishra A, Balkrishnan R. Measuring patients' trust in their primary care providers. Med Care Research and Review. 2002;59:293-318.

36. Sah S, Fugh-Berman A. Physicians under the influence: Social psychology and industry marketing strategies. J Law Med Ethics. 2013;41:665-672.

37. Sah S, Fagerlin A, Ubel P. Effect of physician disclosure of specialty bias on patient trust and treatment choice. Proc Natl Acad Sci. 2016;113:7465-7469.

38. Weinfurt KP, Hall MA, Friedman JY, et al. Effects of disclosing financial interests on participation in medical research: a randomized vignette trial. Am Heart J. 2008; 156:689-97.

39. Weinfurt KP, Hall MA, Dinan MA, DePuy V, Friedman JY, Allsbrook JS, et al. Effects of Disclosing Financial Interests on Attitudes Towards Clinical Research. JGIM. 2008;23:860-66.
40. Santhakumar S, Adashi EY. The Physician Payment Sunshine Act: testing the value of transparency. JAMA. 2015;313:23-24.

41. "Aggregate" payments are for all pharmaceutical and medical device manufacturers for a given fiscal year.

42. Thom DH, Kravitz RL, Bell RA, Kurpat E, Azari R. Patient trust in the physician: relationship to patient requests. Fam Pract. 2002; 19:476-83.

43. Roter DL, Hall JA. Why physician gender matters in shaping the physician-patient relationship. J Women's Health. 1998;7:1093-97.

44. Kesselheim AS, Robertson CT, Siri K, Batra P, Franklin JM. Distribution of industry payments to Massachusetts physicians. N Engl J Med. 2013;368:2049-52.

45. Dugan E, Trachtenberg F, Hall MA. Development of abbreviated measures to assess patient trust in a physician, a health insurer, and the medical profession. BMC Health Serv Res. 2005;5:64.

46. Griner A. Open Payments: a matter of maintaining trust. Health Affairs Blog. February 27, 2014. Available from: http://healthaffairs.org/blog/ 2014/02/27/open-payments-a-matter-of-maintaining-trust/. Accessed May 20, 2017.

47. Steinbrook R, Ross JS. "Transparency reports" on industry payments to physicians and teaching hospitals. JAMA. 2012;307:1029-30.

48. Evans M. How patients will use physician payment data. Morning Consult. 5 October 2014. Available from: http://morningconsult. com/2014/10/health-sunday-10-5/. Accessed May 20, 2017

49. Rosenthal MB, Mello MM. Sunlight as disinfectant-new rules on disclosure of industry payments to physicians. N Engl J Med. 2013;368:2052-4.

50. Sah S, Loewenstein G. Nothing to declare: Mandatory and voluntary disclosure leads advisors to avoid conflicts of interest. Psychol Sci. 2014;25:575-84 